\title{
LESÕES EM DNA INDUZIDAS PELA AUTOXIDAÇÃO DE S(IV) NA PRESENÇA DE ÍONS METÁLICOS DE TRANSIÇÃO
}

\author{
Ruben G. M. Moreno, María V. Alipázaga, Marisa H. G. Medeiros e Nina Coichev* \\ Instituto de Química, Universidade de São Paulo, CP 26077, 05513-970 São Paulo - SP, Brasil
}

Recebido em 22/6/05; aceito em 18/11/05; publicado na web em 14/6/06

\begin{abstract}
DNA DAMAGE INDUCED BY THE AUTOXIDATION OF S(IV) IN THE PRESENCE OF TRANSITION METAL IONS. The oxidation of sulfite catalyzed by transition metal ions produces reactive oxysulfur species that can damage plasmid and isolated DNA in vitro. Among the four DNA bases, guanine is the most sensitive to one-electron oxidation promoted by the species formed in the autoxidation of sulfite $\left(\mathrm{HSO}_{5}^{-}, \mathrm{HO}, \mathrm{SO}_{3}^{-}, \mathrm{SO}_{4}^{-{ }^{-}}\right.$and $\mathrm{SO}_{5}^{-}$) due to its low reduction potential and ability to bind transition metal ions capable to catalyze oxidative processes. Some oxidative DNA lesions are promutagenic and oxidative DNA damage is proposed to play a crucial role in certain human pathologies, including cancer.
\end{abstract}

Keywords: DNA cleavage; oxysulfur radical; transition metal ions.

\section{INTRODUÇÃOO}

O baixo custo, a eficiência e a versatilidade fazem com que o dióxido de enxofre seja largamente utilizado com finalidades industriais. $\mathrm{S}(\mathrm{IV})\left(\mathrm{SO}_{3}{ }^{2-}, \mathrm{HSO}_{3}^{-}\right.$e $\left.\mathrm{H}_{2} \mathrm{SO}_{3}\right)$ é usado como antioxidante em indústrias farmacêuticas e alimentícias ${ }^{1}$. Sulfito é adicionado ao vinho, em concentrações de até de $6 \mathrm{mM}$, devido à sua ação antiséptica e antioxidante. O dióxido de enxofre é adicionado durante a etapa de clarificação do melado da cana de coloração escura e da polpa de celulose em indústrias de celulose e papel. Também tem sido empregado para diminuição da concentração do oxigênio dissolvido em água destinada à geração de vapor e no tratamento de minérios de sulfeto.

Do ponto de vista ambiental, $\mathrm{SO}_{2}$ é um importante poluente atmosférico, oriundo principalmente da combustão de combustíveis fósseis ${ }^{2}$. O dióxido de enxofre, bem como os óxidos de nitrogênio, são os principais precursores da chuva ácida, sendo também responsável pela formação de sulfatos secundários que contribuem para formação do material particulado na atmosfera.

$\mathrm{O}$ aumento da exposição humana ao S(IV) faz com que seus efeitos tóxicos sejam alvo de preocupação crescente por órgãos de controles ligados ao cuidado da saúde humana. Segundo o FDA ("Food and Drug Administration"), uma em cada 100 pessoas e 4 a $8 \%$ dos pacientes asmáticos são sensíveis a $\mathrm{S}(\mathrm{IV})^{3}$. A exposição a S(IV), embora segura para a maioria da população, pode provocar em pessoas hipersensíveis dificuldades respiratórias, choque anafilático e urticária ${ }^{4}$.

No Brasil, a Resolução - RDC no 34 da ANVISA (Agência Nacional de Vigilância Sanitária), de 9 de março de 2001, estabelece os limites máximos de $\mathrm{S}(\mathrm{IV})$ e outros aditivos em alimentos a fim de minimizar os riscos à população. $\mathrm{O}$ limite máximo permitido de sulfito total (expresso em $\mathrm{SO}_{2}$ ) é: $0,035 \mathrm{~g} / 100 \mathrm{~mL}, 0,002 \mathrm{~g} /$ $100 \mathrm{~g}$ e $0,020 \mathrm{~g} / 100 \mathrm{~mL}$ para vinhos, açúcar refinado e sucos de frutas (exceto suco de caju, cujo limite máximo é de $0,3 \mathrm{~g} / 100$ $\mathrm{mL}$ ), respectivamente.

A literatura descreve possíveis efeitos genéticos adversos do S(IV), atuando como agente mutagênico, comutagênico ou carcinogênico ${ }^{5,6}$. O íon sulfito é responsável por alguns dos efeitos

*e-mail: ncoichev@iq.usp.br nocivos às proteínas e ácidos nucléicos, como deaminação da citosina e adição de bisulfito à timina e uracila ${ }^{6}$. Os mecanismos envolvidos na toxicidade do sulfito não estão completamente esclarecidos, mas vários estudos têm sugerido que os radicais de óxidos de enxofre $\left(\mathrm{SO}_{3}{ }^{-}, \mathrm{SO}_{4}^{-}\right.$ou $\mathrm{SO}_{5}{ }^{\circ}$ ) oxidam biomoléculas, incluindo lipídios, proteínas e $\mathrm{DNA}^{7-9}$. Alguns íons metálicos de transição têm um papel importante na formação desses radicais, uma vez que catalisam a oxidação de sulfito pelo oxigênio ${ }^{10,11}$.

\section{Autoxidação de S(IV) catalisada por íons metálicos de transição}

A oxidação de $\mathrm{S}(\mathrm{IV})$ por $\mathrm{O}_{2}$, também chamada de autoxidação, é um processo termodinamicamente favorável; no entanto, esta reação é extremamente lenta, sendo que alguns íons metálicos de transição, ou seus complexos, apresentam efeito catalítico.

A autoxidação de S(IV) catalisada por íons metálicos de transição em meio aquoso tem sido tema de um grande número de estudos $^{10-47}$; a maioria sugere um mecanismo radicalar conforme proposto inicialmente por Backstrom em 1934 ${ }^{21}$.

Obteve-se um grande avanço na compreensão do efeito catalítico de alguns íons metálicos de transição em estudos envolvendo íons metálicos complexados, nos quais foi possível acompanhar a variação do estado de valência do íon metálico. Estudos envolvendo os sistemas Fe(III)/tris 1,10-fenantrolina ${ }^{22}$, $\mathrm{Co}(\mathrm{II}) / \mathrm{Co}(\mathrm{III}) /$ tris $^{23,24}, \mathrm{Co}(\mathrm{II}) /$ $\mathrm{Co}(\mathrm{III}) / \mathrm{NH}_{3}{ }^{25}, \mathrm{Fe}(\mathrm{II}) / \mathrm{Fe}(\mathrm{III}) / \mathrm{EDTA}^{26}, \mathrm{Fe}(\mathrm{II}), \mathrm{Mn}$ (II), $\mathrm{Co}(\mathrm{II}), \mathrm{Ni}(\mathrm{II})$, $\mathrm{Cu}$ (II) e V(IV) com ftalocianinas ${ }^{27}, \mathrm{Mn}$ (III)/CDTA ${ }^{28}, \mathrm{Co}(\mathrm{II}) / \mathrm{Co}(\mathrm{III}) /$ $\mathrm{N}_{3}^{-29,30}, \mathrm{Mn}(\mathrm{II}) / \mathrm{Mn}(\mathrm{III}) / \mathrm{Ac}^{-31}, \mathrm{Mn}(\mathrm{II}) / \mathrm{Mn}(\mathrm{III}) / \mathrm{N}_{3}{ }^{-32}, \mathrm{Ni}(\mathrm{II}) / \mathrm{Ni}(\mathrm{III}) /$ cyclam $^{33,34}, \mathrm{Ni}(\mathrm{OH})_{2} / \mathrm{Ni}(\mathrm{OH})_{3}{ }^{35}, \mathrm{Cu}(\mathrm{II}) / \mathrm{Cu}(\mathrm{III})^{36-41}$ e $\mathrm{Ni}(\mathrm{II}) / \mathrm{Ni}(\mathrm{III})^{34,42}$ com tetraglicina em meio aquoso, indicam que o mecanismo da autoxidação de S(IV) envolve um ciclo de oxidorredução dos íons metálicos, que depende do balanço da concentração de $\mathrm{O}_{2}$ e $\mathrm{S}(\mathrm{IV})^{43,45}$.

Mecanismo da autoxidação de S(IV) catalisada por íons metálicos de transição

O processo catalítico é iniciado pelo íon metálico no estado de valência $3+, \mathrm{M}(\mathrm{III})$. Se o íon metálico estiver presente na forma bivalente $\mathrm{M}(\mathrm{II})$, a geração de $\mathrm{M}(\mathrm{III})$ pode ocorrer pela oxidação com o oxigênio dissolvido (Esquema 1, Equação 1). No caso de $\mathrm{Cu}$ (II) complexado com tetraglicina, Anast e Margerum ${ }^{36}$ sugeri- 
ram uma reação de desproporcionamento (Equação 2). Estudos adicionais realizados por Coichev e colaboradores ${ }^{38-42}$, mostraram um efeito sinérgico com o íon $\mathrm{Ni}(\mathrm{II})$. Dependendo da natureza do íon metálico e do ligante coordenado, pode ocorrer ainda a formação de complexos mistos (Equação 3) $)^{15,39,42}$.

Uma outra possibilidade que deve ser considerada é o íon Fe(III), como iniciador, presente na forma de impureza nos reagentes e na água deionizada $\left(10^{-9} \text { a } 10^{-8} \mathrm{M}\right)^{31,46,47}$.

No início do processo de autocatálise há a redução de $\mathrm{M}(\mathrm{III})$ por $\mathrm{S}(\mathrm{IV})$, gerando o radical $\mathrm{SO}_{3}{ }^{-}$(Equação 4$)$, que rapidamente reage

Início (na ausência de M(III) adicionado)

$$
\begin{aligned}
& \mathrm{M}(\mathrm{II})+\mathrm{O}_{2} \longrightarrow \mathrm{M}(\mathrm{III})+\mathrm{O}_{2} \cdot- \\
& 2 \mathrm{M}(\mathrm{II}) \longrightarrow \mathrm{M}(\mathrm{I})+\mathrm{M}(\mathrm{III}) \\
& \mathrm{M}(\mathrm{II})+\mathrm{SO}_{3}{ }^{2-} \underset{\text { lento }}{\rightleftarrows} \mathrm{M}(\mathrm{II})\left(\mathrm{SO}_{3}\right)_{x} \stackrel{+\mathrm{O}_{2}}{\longrightarrow} \mathrm{M}(\mathrm{III})\left(\mathrm{SO}_{3}\right)_{x}
\end{aligned}
$$

Autocatálise

$$
\begin{aligned}
& \mathrm{M}(\mathrm{III})+\mathrm{SO}_{3}{ }^{2-} \longrightarrow \mathrm{M}(\mathrm{II})+\mathrm{SO}_{3}{ }^{\circ-} \text { lenta } \\
& \mathrm{SO}_{3}{ }^{--}+\mathrm{O}_{2} \longrightarrow \mathrm{SO}_{5}{ }^{--} \\
& \mathrm{M}(\mathrm{II})+\mathrm{SO}_{5}{ }^{--} \longrightarrow \mathrm{M}(\mathrm{III})+\mathrm{SO}_{5}{ }^{2-} \\
& \mathrm{SO}_{5}{ }^{2-}+\mathrm{H}^{+} \longrightarrow \mathrm{HSO}_{5}^{-} \\
& \mathrm{M}(\mathrm{II})+\mathrm{HSO}_{5}^{-} \longrightarrow \mathrm{M}(\mathrm{III})+\mathrm{SO}_{4}{ }^{2-}+\mathrm{HO}^{\circ} \\
& \mathrm{M}(\mathrm{II})+\mathrm{HSO}_{5}{ }^{-} \longrightarrow \mathrm{M}(\mathrm{III})+\mathrm{SO}_{4}{ }^{-}+\mathrm{OH}^{-} \\
& \mathrm{M}(\mathrm{II})+\mathrm{SO}_{4}{ }^{--} \longrightarrow \mathrm{M}(\mathrm{III})+\mathrm{SO}_{4}{ }^{2-}
\end{aligned}
$$

Propagação da Cadeia

$$
\begin{aligned}
& \mathrm{SO}_{5}{ }^{--}+\mathrm{SO}_{3}{ }^{2-} \longrightarrow \mathrm{SO}_{5}{ }^{2-}+\mathrm{SO}_{3}{ }^{--} \\
& \mathrm{SO}_{5}{ }^{--}+\mathrm{SO}_{3}^{2-} \longrightarrow \mathrm{SO}_{4}^{2-}+\mathrm{SO}_{4}^{{ }^{-}} \\
& \mathrm{SO}_{5}{ }^{-}+\mathrm{HSO}_{3}^{-} \longrightarrow \mathrm{HSO}_{5}^{-}+\mathrm{SO}_{3}{ }^{-} \\
& \mathrm{SO}_{5}^{--}+\mathrm{SO}_{5}^{--} \longrightarrow 2 \mathrm{SO}_{4}^{--}+\mathrm{O}_{2} \\
& \mathrm{SO}_{4}{ }^{--}+\mathrm{SO}_{3}{ }^{2-} \longrightarrow \mathrm{SO}_{4}{ }^{2-}+\mathrm{SO}_{3}{ }^{-} \\
& \mathrm{SO}_{4}^{--}+\mathrm{HSO}_{3}^{-} \longrightarrow \mathrm{SO}_{4}^{2-}+\mathrm{SO}_{3}^{{ }^{--}}+\mathrm{H}^{+}
\end{aligned}
$$

Formação dos Produtos / Término da Cadeia

$$
\begin{aligned}
& \mathrm{HSO}_{5}{ }^{-}+\mathrm{SO}_{3}{ }^{2-} \longrightarrow 2 \mathrm{SO}_{4}{ }^{2-}+\mathrm{H}^{+} \\
& \mathrm{HSO}_{5}{ }^{-}+\mathrm{HSO}_{3}^{-} \longrightarrow 2 \mathrm{SO}_{4}{ }^{2-}+2 \mathrm{H}^{+} \\
& \mathrm{SO}_{3}{ }^{\cdot-}+\mathrm{SO}_{3}{ }^{--} \longrightarrow \mathrm{S}_{2} \mathrm{O}_{6}{ }^{2-} \\
& \mathrm{SO}_{4}{ }^{--}+\mathrm{SO}_{4}{ }^{--} \longrightarrow \mathrm{S}_{2} \mathrm{O}_{8}{ }^{2-} \\
& \mathrm{SO}_{5}{ }^{--}+\mathrm{SO}_{5}^{\cdot-} \longrightarrow \mathrm{S}_{2} \mathrm{O}_{8}^{2-}+\mathrm{O}_{2} \\
& \mathrm{SO}_{5}{ }^{--}+\mathrm{SO}_{3}{ }^{--} \longrightarrow \mathrm{S}_{2} \mathrm{O}_{6}{ }^{2-}+\mathrm{O}_{2} \\
& \mathrm{SO}_{5}{ }^{--}+\mathrm{O}_{2}^{--} \longrightarrow \mathrm{SO}_{5}{ }^{2-}+\mathrm{O}_{2} \\
& \mathrm{O}_{2}{ }^{--}+\mathrm{H}^{+} \rightleftarrows \mathrm{HO}_{2}{ }^{\circ} \\
& \mathrm{O}_{2}{ }^{--}+\mathrm{HO}_{2}{ }^{-} \longrightarrow \mathrm{HO}_{2}^{-}+\mathrm{O}_{2} \\
& \mathrm{HO}_{2}^{-}+\mathrm{H}^{+} \rightleftarrows \mathrm{H}_{2} \mathrm{O}_{2} \\
& \mathrm{HSO}_{3}{ }^{-} / \mathrm{SO}_{3}{ }^{2-}+\mathrm{H}_{2} \mathrm{O}_{2} \longrightarrow \mathrm{HSO}_{4}{ }^{-} / \mathrm{SO}_{4}{ }^{2-}+\mathrm{H}_{2} \mathrm{O}
\end{aligned}
$$

$\mathrm{M}=\mathrm{Co}(\mathrm{II}) / \mathrm{Co}(\mathrm{III}) / \mathrm{tris}^{23,24}, \mathrm{Co}(\mathrm{II}) / \mathrm{Co}(\mathrm{III}) / \mathrm{N}_{3}{ }^{29,30}, \mathrm{Mn}(\mathrm{II}) / \mathrm{Mn}(\mathrm{III}) / \mathrm{Ac}^{-31}$, $\mathrm{Mn}(\mathrm{II}) / \mathrm{Mn}(\mathrm{III}) / \mathrm{N}_{3}{ }^{-32}, \mathrm{Ni}(\mathrm{II}) / \mathrm{Ni}(\mathrm{III}) / \mathrm{cyclam}^{33,34}, \mathrm{Ni}(\mathrm{OH})_{2} / \mathrm{Ni}(\mathrm{OH})_{3}{ }^{35}, \mathrm{Cu}(\mathrm{II}) / \mathrm{Cu}(\mathrm{III})^{37-41}$ e $\mathrm{Ni}(\mathrm{II}) / \mathrm{Ni}(\mathrm{III})^{34,42}$ com tetraglicina em meio aquoso.

Esquema 1. Mecanismo da autoxidação de $S(I V)$ catalisada por íons metálicos de transição com o oxigênio para produzir fortes oxidantes como o radical $\mathrm{SO}_{5}{ }^{\circ}$ (Equação 5) e o ânion $\mathrm{HSO}_{5}^{-}$(Equação 7). Estas espécies, por sua vez, oxidam o íon metálico (Equações 6, 8-10) formando $\mathrm{SO}_{4}^{-{ }^{-}} \mathrm{e}$ $\mathrm{HO}^{*}$. Após estas reações, seguem etapas de propagação em cadeia nas quais alguns dos produtos finais são $\mathrm{SO}_{4}{ }^{2-}, \mathrm{S}_{2} \mathrm{O}_{6}{ }^{2-} \mathrm{e}_{2} \mathrm{O}_{8}{ }^{2-}$ (Equações $11-27)^{21,29}$.

\section{LESÃO EM DNA INDUZIDA PELA AUTOXIDAÇÃO DE SULFITO NA PRESENÇA DE ÍONS METÁLICOS DE TRANSIÇÃO}

Alguns estudos mostram que o íon sulfito pode provocar lesão no DNA, com baixo rendimento. Diversos estudos in vitro ${ }^{6}$ indicam que os radicais $\mathrm{SO}_{3}^{-}{ }^{-}$e $\mathrm{SO}_{4}^{-}$reagem com ácidos nucléicos produzindo 8-oxo-7,8-diidro-2'-deoxiguanosina (8-oxodGuo), quebra das fitas do $\mathrm{DNA}^{48}$ e da ligação proteína - DNA.

Segundo alguns autores, a guanina seria um alvo preferencial para sofrer oxidação devido a seu baixo potencial de redução (Tabela 1) e a sua habilidade para se ligar a íons metálicos de transição capazes de catalisarem processos oxidativos ${ }^{49,50}$.

Entretanto, os radicais formados na autoxidação de S(IV) podem provocar lesões em outras biomoléculas e estruturas celulares dependendo da reatividade, proximidade de geração com a molécula alvo e presença de antioxidantes. Tais lesões, se não reparadas, podem comprometer o funcionamento da célula.

A seguir são apresentados os estudos específicos de lesão no DNA pelas possíveis espécies formadas $\left(\mathrm{HSO}_{5}^{-}, \mathrm{HO}^{*}, \mathrm{SO}_{3}{ }^{-}, \mathrm{SO}_{4}{ }^{-}\right.$ e $\mathrm{SO}_{5}^{-}$) na autoxidação de sulfito (Esquema 1).

Tabela 1. Potencial de redução de alguns óxidos de enxofre (vs E.N.H. $)^{11,51}$

\begin{tabular}{lcc}
\hline Par redox & $E^{\circ}(\mathrm{V})$ & $\mathrm{pH}$ \\
\hline $\mathrm{SO}_{3}^{--} / \mathrm{SO}_{3}^{2-}$ & $0,63-0,89$ & $>7,0$ \\
$\mathrm{SO}_{3}^{--} / \mathrm{SO}_{3}^{2-}$ & 0,84 & 3,6 \\
$\mathrm{SO}_{4}^{--} / \mathrm{SO}_{4}^{2-}$ & $2,43-3,08$ & - \\
$\mathrm{SO}_{4}^{2-} / \mathrm{SO}_{3}^{2-}$ & $-0,93$ & - \\
$\mathrm{SO}_{4}^{2-} / \mathrm{H}_{2} \mathrm{SO}_{3}$ & 0,172 & - \\
$\mathrm{SO}_{5}^{--} / \mathrm{HSO}_{5}^{-}$ & 1,1 & 7,0 \\
$\mathrm{HSO}_{5}^{-} / \mathrm{HSO}_{4}^{-}$ & $1,81-1,842$ & - \\
$\mathrm{HSO}_{5}^{-} / \mathrm{SO}_{4}^{2-}$ & 1,75 & $3-9$ \\
$\mathrm{SO}_{5}^{2-} / \mathrm{SO}_{4}^{2-}$ & 1,22 & $>10$ \\
$\mathrm{HO}^{-} / \mathrm{H}_{2}$ & 2,31 & 7 \\
$\mathrm{G}^{-+} / \mathrm{G}^{*+} / \mathrm{A}$ & 1,29 & 7 \\
$\mathrm{C}^{-+} / \mathrm{C}$ & 1,42 & 7 \\
$\mathrm{~T}^{\circ+} / \mathrm{T}$ & 1,60 & 7 \\
8-OxoG & 1,70 & 7 \\
8-oxodA / 8-oxoG & 0,58 & 8 \\
\hline
\end{tabular}

$\mathrm{O}$ radical sulfito $\left(\mathrm{SO}_{3}^{-}\right.$) pode ser gerado nas células pela oxidação de $\mathrm{SO}_{3}{ }^{2-}$ mediada por enzimas ou por oxidação pelo oxigênio ${ }^{52,53}$. Tem sido relatado que metionina é oxidada a seu sulfóxido correspondente, em $\mathrm{pH}$ neutro, durante a oxidação aeróbica de $\mathrm{SO}_{3}{ }^{-54}$. O radical sulfito também provoca a oxidação de $\beta$-caroteno, triptofano ${ }^{54,55}$ e forma compostos de adição à dupla ligação em alcenos ${ }^{56}$.

Experimentos realizados por Shi e $\mathrm{Mao}^{48}$ mostram que a incubação de solução de sulfito com DNA por $4 \mathrm{~h}$ causa rendimento baixo de produção de lesão, no entanto, na presença de $\mathrm{Cr}(\mathrm{VI})$ são observados níveis maiores de quebra da dupla fita do DNA. Segundo esses autores, a oxidação de sulfito na presença de $\mathrm{Cr}(\mathrm{VI})$ gera somente o radical $\mathrm{SO}_{3}{ }^{--}$, não sendo detectada a formação do radical 
HO'. Desta maneira, foi sugerido que o radical $\mathrm{SO}_{3}{ }^{-}$pode ser o responsável pela lesão no $\mathrm{DNA}^{48}$. No entanto, na presença desses reagentes deve haver a formação de outros radicais capazes de causarem a quebra observada da dupla fita do DNA e oxidação da 2'deoxiguanosina (dGuo).

$\mathrm{O}$ mecanismo proposto por Shi e $\mathrm{Mao}^{48}$ para a formação de 8 hidroxi-2'-deoxiguanosina (8 OHdGuo) envolvendo radicais $\mathrm{SO}_{3}{ }^{-}$ está representado nas Equações 28 - 30. Este mecanismo mostra a formação dos intermediários $\mathrm{dGuo}^{*+}$ e dGuoHO', os quais também podem reagir com água ou outros solventes, como por ex. álcoois.

$\mathrm{dGuO}+\mathrm{SO}_{3}^{--} \longrightarrow \mathrm{dGuo}^{-+}+\mathrm{SO}_{3}^{2-}$

$\mathrm{dGuO}^{*+}+\mathrm{H}_{2} \mathrm{O} \longrightarrow \mathrm{dGuoHO}+\mathrm{SO}_{3}^{2-}+\mathrm{H}^{+}$

$\mathrm{dGuoHO}+\mathrm{SO}_{3}{ }^{-} \longrightarrow \mathrm{dGuoO}(8-\mathrm{OHdGuo})+\mathrm{SO}_{3}{ }^{2-}+\mathrm{H}^{+}$

Kawanishi et al. ${ }^{59}$ observaram uma modificação específica na dupla hélice do DNA, centrada na guanina, na presença de $\mathrm{CoCl}_{2}$, sulfito (1-2 mM) e oxigênio. Essa modificação foi atribuída à formação de $\mathrm{SO}_{4}{ }^{-}$. No entanto, quando o íon metálico empregado foi $\mathrm{Cu}$ (II), uma clivagem aleatória maior no DNA foi sugerida a partir da oxidação de DNA por $\mathrm{SO}_{3}{ }^{--}$.

Alguns autores sugerem que $\mathrm{SO}_{4}^{-}$, e não $\mathrm{SO}_{3}{ }^{-}$, é o responsável pela lesão observada no DNA em meio contendo [NiKGH-CONH$]_{2}{ }^{+}$ $\left(\mathrm{KGH}=\right.$ lisilglicil-histidina) e sulfito ${ }^{7}$. No entanto, outras espécies, como peroxomonosulfato $\left(\mathrm{SO}_{5}{ }^{2}\right.$ ), necessitam também ser consideradas $^{9}$. Desta forma, foram realizados estudos com $[\mathrm{NiCR}]^{2+}(\mathrm{CR}=$ 2,12-dimetil-3,7,11,17-tetraazabiciclo[11,3,1]-heptadecano$1(17), 2,11,13,15$-pentaeno) e $\left[\mathrm{NiKGH}-\mathrm{CONH}_{2}\right]^{+}$para verificar a participação de $\mathrm{SO}_{5}^{--}$, com base nas equações postuladas por Coichev e van Eldik (Esquema 1, Equações. 4 -10) para as etapas de início e propagação da cadeia ${ }^{29}$.

Considerando os potenciais de redução, ambos complexos $\left[\mathrm{Ni}^{\mathrm{II}} \mathrm{KGH}-\mathrm{CONH}_{2}\right]^{2+}(0,9 \mathrm{~V}$ vs. E.N.H. $)$ e $\left[\mathrm{Ni}^{\mathrm{II}} \mathrm{CR}\right]^{3+}(1,3 \mathrm{~V}$ vs. E.N.H. $)^{7}$ podem oxidar $\mathrm{SO}_{3}{ }^{2-}$ a $\mathrm{SO}_{3}{ }^{-}\left(\mathrm{E}^{\circ} \mathrm{SO}_{3}{ }^{-}-/ \mathrm{SO}_{3}{ }^{2-} \sim 0,63 \mathrm{~V}\right.$ vs. E.N.H., Equação. 4) ${ }^{9}$. $\mathrm{O} \mathrm{SO}_{3}{ }^{-}$formado reage rapidamente com $\mathrm{O}_{2}$ para formar $\mathrm{SO}_{5}{ }^{-}$(Equação 5). Assim, $\mathrm{O} \mathrm{SO}_{5}^{-}$formado $\left(\mathrm{E}^{\circ} \mathrm{SO}_{5}^{-}{ }^{-} /\right.$ $\mathrm{SO}_{5}{ }^{2-} \sim 1,1 \mathrm{~V}$ vs. E.N.H.) pode oxidar o complexo $\left[\mathrm{Ni}^{\mathrm{II}} \mathrm{KGH}-\right.$ $\left.\mathrm{CONH}_{2}\right]^{+}$(Equação 6) gerando $\left[\mathrm{Ni}^{\amalg I} \mathrm{KGH}-\mathrm{NH}_{2}\right]^{2+}$ e $\mathrm{SO}_{5}^{2-}$. $\mathrm{HSO}_{5}$ também pode oxidar $\left[\mathrm{Ni}^{\mathrm{II}} \mathrm{KGH}-\mathrm{NH}_{2}\right]^{+}$(Equações 8 e 9). No entanto, a oxidação do complexo de $\left[\mathrm{Ni}^{\mathrm{II}} \mathrm{CR}\right]^{2+}$ por $\mathrm{SO}_{5}{ }^{-}$(Equação 6) não é favorável (deduzido a partir dos potenciais de redução), havendo conseqüentemente a reação de dimerização do $\mathrm{SO}_{5}{ }^{--}$para produzir $\mathrm{SO}_{4}^{--}$e $\mathrm{O}_{2}$ (Equação 14) ${ }^{8,9}$. O radical $\mathrm{SO}_{4}^{--}$, que pode também ser formado como na Equação 9, possui um potencial de redução suficientemente alto $(2,43-3,08 \mathrm{~V}$ vs E.N.H.) para oxidar os dois complexos de Ni(II). ${ }^{7}$

Muller e colaboradores ${ }^{9}$, em estudos de lesões no DNA induzidas pela autoxidação de sulfito catalisada por alguns complexos de $\mathrm{Ni}(\mathrm{II})$, discutiram a reatividade dos diferentes radicais. $\mathrm{O}$ radical $\mathrm{SO}_{3}^{-}$, produto inicial (Equação 4), seria um agente improvável para lesar o DNA, devido ao tempo de vida curto na presença de oxigênio (Equação 5), além disso, seu potencial de redução $\left(\mathrm{E}^{\circ} \mathrm{SO}_{3}{ }^{-} / \mathrm{SO}_{3-2} \sim 0,63 \mathrm{~V}\right.$ vs E.N.H.) é baixo para a oxidação de um elétron da guanina, cujo potencial de redução é $\mathrm{E}_{\mathrm{G} / \mathrm{G}}^{\circ}=1,14-1,24 \mathrm{~V}$ vs E.N.H.

As propriedades do radical $\mathrm{SO}_{5}{ }^{-}$não são bem conhecidas, no entanto, a sua reatividade alta à reação de dimerização leva à formação de $\mathrm{SO}_{4}{ }^{-}$(Equação 14). Por outro lado, seu potencial de redução baixo $\left(\mathrm{E}_{\mathrm{SO}_{5}^{-}}^{\circ} / \mathrm{HSO}_{5}^{-} \sim 1,1 \mathrm{~V}\right.$ vs. E.N.H.) comparado com a guanina e sua reatividade baixa com etanol $\left(\mathrm{k}<10^{3} \mathrm{M}^{-1} \mathrm{~s}^{-1}\right)$ mostraram que este radical é o agente lesivo ao DNA menos viável ${ }^{9}$.

$\mathrm{SO}_{4}^{--}$ou $\mathrm{HSO}_{5}^{-}$, os oxidantes mais potentes, podem oxidar os quatro nucleosídeos no DNA. No entanto, no caso de Ni(II) complexado com peptídeos $\left(\left[\mathrm{NiKGH}-\mathrm{NH}_{2}\right]^{+},[\mathrm{NiCR}]^{2+}\right){ }^{9}$ foi observada uma alta seletividade na oxidação da guanina, em comparação com os outros nucleosídeos.

Segundo Burrows e Muller ${ }^{51}$, a identificação dos radicais $\left(\mathrm{SO}_{3}{ }^{-}\right.$ , $\mathrm{SO}_{5}^{--}$e $\mathrm{HSO}_{5}^{-}$, gerados a partir da autoxidação de sulfito na presença de íons metálicos de transição) envolvidos na oxidação dos ácidos nucléicos é difícil.

A reação do $\mathrm{SO}_{5}{ }^{--}$com nucleosídeos é desconhecida, mas a reação dos complexos de $\mathrm{Cu}(\mathrm{II})$ e $\mathrm{Ni}(\mathrm{II})$ com $\mathrm{HSO}_{5}$ - pode produzir $\mathrm{SO}_{4}^{2-}$ e $\mathrm{HO}^{*}$ (Equações 8 e 9) ${ }^{36,39}$, este último um forte oxidante, capaz de lesar diversas biomoléculas.

Na literatura, encontram-se vários estudos da lesão causada no DNA pela autoxidação de sulfito na presença de complexos de $\mathrm{Mn}(\mathrm{II})^{59-62}, \mathrm{Cr}(\mathrm{VI})^{60,63}, \mathrm{Fe}(\mathrm{III})^{8,59,60,64}, \mathrm{Co}(\mathrm{II})^{9,59,65}, \mathrm{Ni}(\mathrm{II})^{7,49,60,64-68}$ e $\mathrm{Cu}(\mathrm{II})^{49,59,65}$. Foi sugerido que ocorre oxidação específica da base da guanina, pela geração de $\mathrm{SO}_{4}^{-51}$.

Estudos sistemáticos de ligantes macrocíclicos coordenados ao Ni(II), mostraram a importância do tamanho do anel, grau de insaturação, efeito estérico e potencial de oxidorredução, na capacidade de ligação ao DNA afetando sua reatividade ${ }^{69}$.

Coichev e colaboradores ${ }^{70}$ investigaram a lesão oxidativa no DNA na presença de sulfito e complexos de $\mathrm{Cu}$ (II)/Cu(III)/tetraglicina. Estes estudos combinados com um estudo cinético detalhado e a elucidação do mecanismo da reação contribuíram para evidenciar que uma parte do $\mathrm{Cu}(\mathrm{III}) /$ tetraglicina formado permanece em solução contendo o DNA. Estudos por EPR ${ }^{71}$ permitiram verificar a formação dos radicais $\mathrm{SO}_{3}^{-}$e $\mathrm{HO}^{*}$ durante a reação estudada. Embora os radicais $\mathrm{SO}_{4}{ }^{-}$ e $\mathrm{SO}_{5}^{-}$não tenham sido detectados, a participação destas espécies, no mecanismo de lesão no DNA, não pode ser descartada. O captador de spin usado (DMPO = 5,5 dimetil-1-pirrolina- $N$-óxido), presente em excesso suficiente quando a reação foi iniciada, possivelmente deve ter captado todo o radical sulfito assim que este se formou, não permitindo a subseqüente formação dos outros radicais.

\section{Lesão no DNA por $\mathrm{HSO}_{5}$ -}

Experimentos nos quais a espécie de enxofre foi adicionada na forma de $\mathrm{S}(\mathrm{VIII})$, ( $\mathrm{HSO}_{5}$; $\left.\mathrm{SO}_{5}{ }^{2-}\right)$, um forte oxidante (Tabela 1), na presença de íons complexos também foram realizados.

Foi proposto que na reação de $\mathrm{HSO}_{5}^{-} \operatorname{com}\left[\mathrm{Co}\left(\mathrm{H}_{2} \mathrm{O}\right)_{6}\right]^{2+}$ há a formação de $\mathrm{SO}_{4}^{-}{ }^{-}$(Equações 31 - 36) e na presença de DNA há uma lesão oxidativa na dupla fita do DNA, preferencialmente na guanina $^{49,50}$. Outros ligantes coordenados ao íon cobalto foram utilizados para verificar a lesão no DNA. Observou-se que a intensidade da lesão obedece a ordem: $\left[\mathrm{Co}\left(\mathrm{H}_{2} \mathrm{O}\right)_{6}\right] \mathrm{Cl}_{2} \gg\left[\mathrm{Co}\left(\mathrm{NH}_{3}\right)_{5} \mathrm{Cl}_{1} \mathrm{Cl}_{2}\right.$ $>\left[\mathrm{Co}(\right.$ cyclam $\left.) \mathrm{Cl}_{2}\right] \mathrm{Cl}>\left[\mathrm{Co}(\text { bipy })_{3}\right]\left(\mathrm{ClO}_{4}\right)_{3}>\left[\mathrm{Co}\left(\mathrm{NH}_{3}\right)\right]\left(\mathrm{ClO}_{4}\right)_{3}$. As espécies de $\mathrm{Co}$ (III) possuem um potencial de redução alto, o qual é crucial na decomposição de $\mathrm{HSO}_{5}^{-}$, sendo o $\mathrm{HSO}_{5}^{-}$oxidado a radical peroxomonosulfato, $\mathrm{SO}_{5}^{-{ }^{-50}}$. O potencial de redução de $\mathrm{SO}_{5}{ }^{-1}$ / $\mathrm{HSO}_{5}$ - foi estimado em 1,1 V (vs. E.N.H.), enquanto que os complexos de cobalto (III) citados possuem potenciais de redução ( $\mathrm{Co}^{\mathrm{III}}$ / $\left.\mathrm{Co}^{\mathrm{II}}\right)<1,0 \mathrm{~V}$ (vs. E.N.H.) $)^{50}$. Desta maneira, foi sugerido que a espécie gerada, $\mathrm{SO}_{4}^{-*}$, pela reação dos complexos $\mathrm{Co}\left(\mathrm{II} /(\mathrm{III})\right.$ e $\mathrm{HSO}_{5}^{-}$é a responsável pela oxidação da guanina ${ }^{69}$.

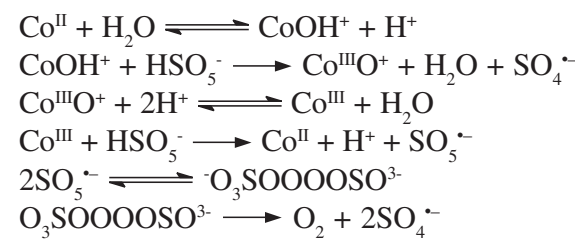

(Obs: Nas Equações 31 - 36, íons de cobalto estão complexados com os ligantes citados no parágrafo anterior $)^{50}$. 
A partir da reação de $\mathrm{HSO}_{5}^{-}$com o complexo de $[\mathrm{Ni}(\text { cyclam })]^{2+}$ (cyclam $=1,4,8,11$-tetraazociclotetradecano) foi proposto um mecanismo que envolve a oxidação direta de $[\mathrm{Ni}(\text { cyclam })]^{2+}$ por $\mathrm{HSO}_{5}^{-}$, para formar $\mathrm{SO}_{4}^{-}$e $\mathrm{OH}^{-}$, bem como espécies intermediárias nas quais o metal central é $\mathrm{Ni}(\mathrm{III})$ (Equação 37). O Ni(III) com a configuração eletrônica $\mathrm{d}^{7}$ tende a formar complexos com estrutura tetragonal hexa-coordenada. Assim, na presença de DNA, os autores sugeriram que o nitrogênio N7 da guanina possivelmente se coordena ao $\mathrm{Ni}(\mathrm{III})$ em um mecanismo de esfera interna ${ }^{69}$.

$\mathrm{HSO}_{5}^{-}+[\text {Nicyclam }]^{2+} \longrightarrow[\text { Nicyclam }]^{3+}+\mathrm{SO}_{4}^{-}+\mathrm{OH}^{-}$

Estudos adicionais de $\mathrm{HSO}_{5}^{-}$na presença de íon brometo mostraram a ocorrência de uma halogenação das pirimidinas. $\mathrm{O}$ interesse nesses estudos refere-se às propriedades bioquímicas e biofísicas que os nucleotídeos halogenados têm mostrado, tais como efeitos inibidores no crescimento de bactérias e tumores ${ }^{72}$.

Burrows e colaboradores ${ }^{73}$ nos estudos da oxidação de DNA, mediados por íons metálicos de transição, mostraram que uma reação específica para citosina pode acontecer utilizando íon brometo e $\mathrm{HSO}_{5}^{-}$, mistura essa que lesa o DNA após tratamento com piperidina. $\mathrm{O}$ mecanismo sugerido para esta reação procede via geração de $\mathrm{Br}_{2}$ in situ, com posterior adição de $\mathrm{Br}$ e $\mathrm{OH}$ à dupla ligação 5,6 respectivamente.

$\mathrm{O}$ radical sulfato $\left(\mathrm{SO}_{4}^{-}\right)$, um oxidante extremamente forte ${ }^{49,50,59,65,66,74}$, é capaz de oxidar guanosina e modificar a dupla hélice do DNA com preferência pela guanina ${ }^{49,64,65}$. A constante de velocidade para a reação de $\mathrm{SO}_{4}^{-}$com dGuo $\left(2,3 \times 10^{9} \mathrm{M}^{-1} \mathrm{~s}^{-1}\right)$ é 10 vezes maior que com algum outro deoxinucleosideo ${ }^{65}$ e aproximadamente 100 vezes maior que a oxidação do açúcar (D-ribose, 3,8 x $10^{7} \mathrm{M}^{-1} \mathrm{~s}^{-1}$ ). Assim, o radical sulfato formado pela decomposição catalítica de $\mathrm{HSO}_{5}^{-}$por $\mathrm{Co}(\mathrm{II})^{50,59,65}$ poderia supostamente oxidar predominantemente resíduos guanina no $\mathrm{DNA}^{65}$. Estes resultados foram comparados com outros estudos nos quais a produção de radicais sulfato foi realizada via fotólise de persulfato $\left(\mathrm{S}_{2} \mathrm{O}_{8}{ }^{2-}\right)^{74}$, onde se observou que a clivagem padrão (seguida por tratamento com piperidina) foi essencialmente igual àquela obtida com o sistema $\mathrm{Co}(\mathrm{II}) / \mathrm{KHSO}_{5}$ e com modificação específica na guanina ${ }^{65}$. Estes resultados apóiam a idéia de que o radical $\mathrm{SO}_{4}{ }^{-}$é produzido a partir da reação de sulfito com oxigênio na presença de $\mathrm{Co}(\mathrm{II})$ e causa a alteração na guanina ${ }^{59,65}$.

Em comparação com radicais hidroxila (que causam clivagem na fita do DNA preferencialmente nas posições guanina e timina) ${ }^{63}$, os radicais sulfato têm menor tendência para reagir com as duplas ligações da timina ${ }^{75}$. Nakayama e colaboradores ${ }^{76}$ relataram que o orbital molecular ocupado de nível de energia maior da guanina é o mais energético entre as bases dos ácidos nucléicos, sendo portanto oxidada mais facilmente. A predominância da alteração da guanina pela reação de $\mathrm{Co}(\mathrm{II}) / \mathrm{KHSO}_{5}$ pode ser atribuída ao $\mathrm{SO}_{4}^{--}$, que é o agente oxidante efetivo de transferência de elétrons ${ }^{77-79}$.

\section{Lesão em DNA provocada por alguns radicais de óxidos de enxofre em meio alcoólico}

Foram realizados estudos em meio alcoólico, com finalidade de evidenciar a formação de radicais $\mathrm{SO}_{4}{ }^{-}$e também investigar o possível envolvimento de $\mathrm{SO}_{3}{ }^{--}$e $\mathrm{SO}_{5}{ }^{--}$na lesão no $\mathrm{DNA}^{8,9,48,50,59,65}$.

Foi sugerido que $\mathrm{SO}_{4}^{--}$reage facilmente com etanol, enquanto $\mathrm{SO}_{3}{ }^{-} \mathrm{e} \mathrm{SO}_{5}^{-{ }^{-}}$reagem 10 mil vezes mais lentamente ${ }^{8,9,65}$. Além disso, o álcool t-butanol reage cerca de 1000 vezes mais rápido com radical hidroxila que com os radicais de sulfito ${ }^{8,9,65}$. Estudos de Muller e colaboradores ${ }^{8}$ revelaram que o radical $\mathrm{HO}^{\bullet}$ reage com álcoois (etanol e t-butanol), e o radical $\mathrm{SO}_{4}^{-}$é seqüestrado somente por etanol e reage 100 vezes mais lentamente com t-butanol. Surpreendentemente, a adição de etanol ou t-butanol permitiu um aumento na reatividade do DNA (50 e 7\%, respectivamente) $)^{8,59}$.

A adição de $25 \mathrm{mM}$ de etanol a uma reação de $\mathrm{CoCl}_{2}, \mathrm{HSO}_{5}^{-}$e oligodeoxinucleotideos, d(ATATCAGATCTAGACTAT) (Tabela 2), leva a uma inibição de cerca de $89 \%$ em relação à incubação na ausência de álcool ${ }^{50}$. Concentrações maiores de etanol, 50 ou 100 $\mathrm{mM}$, reduzem em $95 \%$ a ocorrência de quebra em fita de DNA. Entretanto, em experimentos análogos utilizando o t-butanol não foi observada inibição da lesão. Outros resultados obtidos com $[\mathrm{NiCR}]^{2+}$ e $\left[\mathrm{NiKGH}-\mathrm{CONH}_{2}\right]+$ estão apresentados na Tabela 2.

Tabela 2. Variações na $\%$ de quebra da fita de $\mathrm{DNA}^{\mathrm{a}}$ em meio alcoólico.Reproduzida da ref. 50 com permissão da "The American Chemical Society"

\begin{tabular}{llc}
\hline Reagentes & Álcool & $\begin{array}{r}\text { Variação da clivagem } \\
\text { ao DNA }(\%)^{\mathrm{b} *}\end{array}$ \\
\hline Fotólise de $\mathrm{K}_{2} \mathrm{~S}_{2} \mathrm{O}_{8}$ & $25 \mathrm{mM}$ etanol & -80 \\
& $50 \mathrm{mM}$ etanol & -84 \\
& $100 \mathrm{mM}$ etanol & -90 \\
& $25 \mathrm{mM}$ t-butanol & +21 \\
& $50 \mathrm{mM}$ t-butanol & +17 \\
$\mathrm{CoCl}_{2}{ }^{\mathrm{c}}+\mathrm{KHSO}_{5}{ }^{\mathrm{d}}$ & $100 \mathrm{mM}$ t-butanol & -08 \\
& $25 \mathrm{mM}$ etanol & -89 \\
& $50 \mathrm{mM}$ etanol & -97 \\
& $100 \mathrm{mM}$ etanol & -95 \\
& $25 \mathrm{mM}$ t-butanol & +05 \\
& $50 \mathrm{mM}$ t-butanol & +05 \\
& $100 \mathrm{mM}$ t-butanol & -01 \\
$\mathrm{NiCR}^{\mathrm{c}}+\mathrm{KHSO}_{5}{ }^{\mathrm{d}}$ & $25 \mathrm{mM}$ etanol & -12 \\
& $50 \mathrm{mM}$ etanol & -24 \\
& $100 \mathrm{mM}$ etanol & -48 \\
& $25 \mathrm{mM}$ t-butanol & +09 \\
& $50 \mathrm{mM}$ t-butanol & +03 \\
& $100 \mathrm{mM}$ t-butanol & +03 \\
\hline
\end{tabular}

a Oligodeoxinucleotideo, d(ATATCAGATCTAGACTAT) $3 \mu \mathrm{M}$.

${ }^{\mathrm{b}}$ Erro estimado em $\pm 10 \%$. ${ }^{\mathrm{c}}[\mathrm{NiCR}]$ e $\left[\mathrm{CoCl}_{2}\right]=3 \mu \mathrm{M} .{ }^{\mathrm{d}}\left[\mathrm{KHSO}_{5}\right]$ $=50 \mathrm{mM}$ * variação da clivagem ao DNA = diferença da clivagem com e sem álcool.

Experiências em meio de $25 \mathrm{mM}$ de etanol ou t-butanol, com produção fotolítica de radical sulfato, mostraram uma redução de $80 \%$ e um aumento de $21 \%$, respectivamente, nas quebras da fita de DNA mediada por radical sulfato ${ }^{50}$.

Estas observações para a modificação de DNA a partir de $\mathrm{CoCl}_{2}$ e $\mathrm{HSO}_{5}{ }^{-}$parecem ser consistentes com a produção maior de radical sulfato $\left(\mathrm{SO}_{4}^{--}\right)$que a dos radicais peroxomonosulfato $\left(\mathrm{SO}_{5}^{-}\right)$e hidroxila ( $\left.\mathrm{HO}^{\circ}\right)$.

No entanto, outros resultados obtidos com $\mathrm{NiCR}$ e $\mathrm{HSO}_{5}^{-}$foram diferentes ${ }^{50}$. Quando $25 \mathrm{mM}$ de etanol foi adicionado ao DNA na presença de $\mathrm{NiCR}_{\text {e }} \mathrm{HSO}_{5}^{-}$a diferença na proporção da quebra da fita, na presença de álcool, diminuiu somente em $12 \%$, enquanto a adição de $100 \mathrm{mM}$ de etanol resultou em uma redução de $48 \%{ }^{50}$. Esses dados podem sugerir que enquanto a reação envolvendo $\mathrm{CoCl}_{2}$ produz uma quantidade alta de radical sulfato, reações empregando NiCR podem envolver um intermediário no qual o complexo de níquel (III) liga-se a $\mathrm{SO}_{4}^{*-}$ produzindo efetivamente um complexo misto com o radical sulfato, o qual pode ser formado desde a sua geração na presença de etanol (Equações 38 e 39).

$\left[\mathrm{Co}^{\mathrm{II}}\left(\mathrm{H}_{2} \mathrm{O}\right)_{5} \mathrm{~L}\right]^{2+}+\mathrm{HSO}_{5}^{-} \longrightarrow\left[\mathrm{Co}^{\mathrm{III}}\left(\mathrm{H}_{2} \mathrm{O}\right)_{4}(\mathrm{OH}) \mathrm{L}^{2+}+\mathrm{SO}_{4}^{-}+2 \mathrm{H}^{+}(38)\right.$ 
$\mathrm{L}=\mathrm{H}_{2} \mathrm{O}$ ou $\mathrm{G}$ N7 do DNA

$\left[\mathrm{Ni}^{\mathrm{II} C R}\right]^{2+}+\mathrm{HSO}_{5}^{-} \longrightarrow\left[\mathrm{Ni}^{\mathrm{III}} \mathrm{CR}(\mathrm{L})\left(\mathrm{SO}_{4}\right)\right]^{2+}+\mathrm{OH}^{-}$

$\mathrm{L}=\mathrm{G}$ N7 de DNA

\section{PRODUTOS RESULTANTES DA OXIDAÇÃO DO DNA}

Como mencionado anteriormente, dentre as espécies formadas a partir da autoxidação do sulfito $\left(\mathrm{SO}_{3}^{-}, \mathrm{SO}_{4}^{-}, \mathrm{SO}_{5}^{-}, \mathrm{HO}^{-}\right.$e $\left.\mathrm{HSO}_{5}^{-}\right)$, o radical sulfato é a espécie mais reativa devido ao maior potencial de redução (Tabela 1) e é apontada como a espécie mais provável de promover lesão no DNA, reagindo com a base de menor potencial de redução, a guanina ${ }^{51}$ (Tabela 1). No entanto, um dos seus produtos de oxidação, 8-oxodG, também pode ser oxidado, sendo o seu potencial de redução menor ainda, $0,58 \mathrm{~V}^{48,51,64,80}$ (vs E.N.H., Tabela 1).

A maioria dos oxidantes reage com a guanina por mecanismo de um elétron, levando à formação do cátion radical $\mathrm{G}^{\circ+}$ que, após sofrer hidratação seguida de oxidação por um elétron, forma a 8oxodG (Figura 1, composto A). Por outro lado, o cátion radical da guanina desprotonado $(\mathrm{G}-\mathrm{H})^{\bullet}$ não sofre hidratação, entretanto, adições de $\mathrm{O}_{2}$ no radical centrado no $\mathrm{C}_{5}$ levam a uma seqüência de reações que conduz à formação de imidazolona (Figura 1, composto E) e oxazolona ${ }^{51,81}$ (Figura 1, composto F).

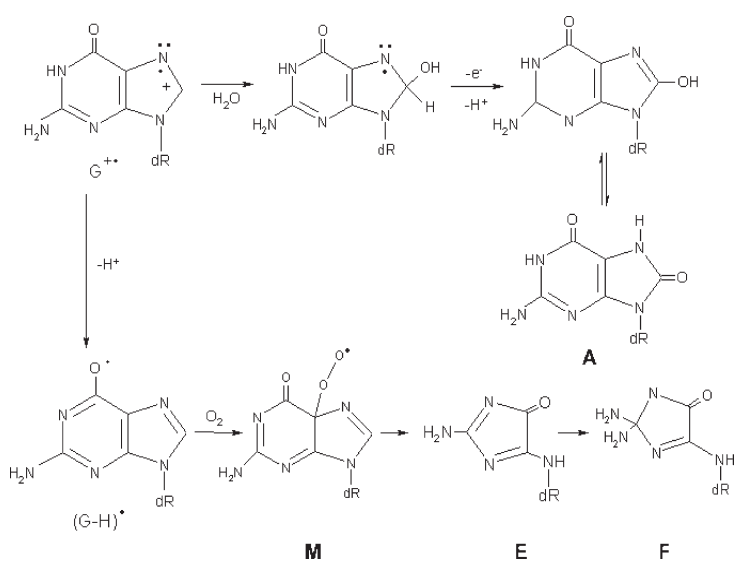

Figura 1. Produtos secundários formados a partir do cátion radical guanina. (A) 8-oxodG; (M) forma ressonante de $(G-H)$; $(\boldsymbol{E})$ Imidazolona e $(\boldsymbol{F})$ Oxazolona. dR: desoxirribose. Reproduzida da ref. 51 com permissão da "The American Chemical Society"

Estudos sugerem que os níveis bases de 8-oxodGuo em células humanas são de 0,3 - 4,2 8-oxodGuo por $10^{6} \mathrm{G}^{82}$. Portanto, a química relacionada a 8-oxodG é de interesse particular. 8-oxodG ou a sua forma tautomérica, 7,8-diidro-8-hidroxoguanina, podem ser formadas até por 4 reações diferentes (Figura 2). Assim, $\mathrm{C}_{8}$ parece ser susceptível à adição de radical $\mathrm{HO}^{\circ}{ }^{51}$, como é indicado na Figura 2 (reação 1).

Finalmente, uma outra reação de oxidação da guanina seria possível a partir de espécies oxo metálicas capazes de transferir átomos de oxigênio ${ }^{51}$ (Figura 2, reação 4).

\section{LESÃO NO DNA POR HO•}

Tem sido demonstrado que o produto principal da oxidação da dGuo por HO` em solução aquosa aerada é o 2,2-diamino-4-[(2deoxi- $\beta$-D-eritro-pentofuranosil) amino]-5 (2H)-oxazolona (dZ), juntamente com seu precursor lábil, o 2-amino-5-[(2-deoxi- $\beta$-Deritro-pentofuranosil) amino]-4H-Imidazo-4-ona (Figura 3).

$\mathrm{O}$ radical $\mathrm{HO}^{*}$ produzido pela autoxidação de $\mathrm{S}(\mathrm{IV})$ também deve ser considerado como um possível agente de lesão no DNA,

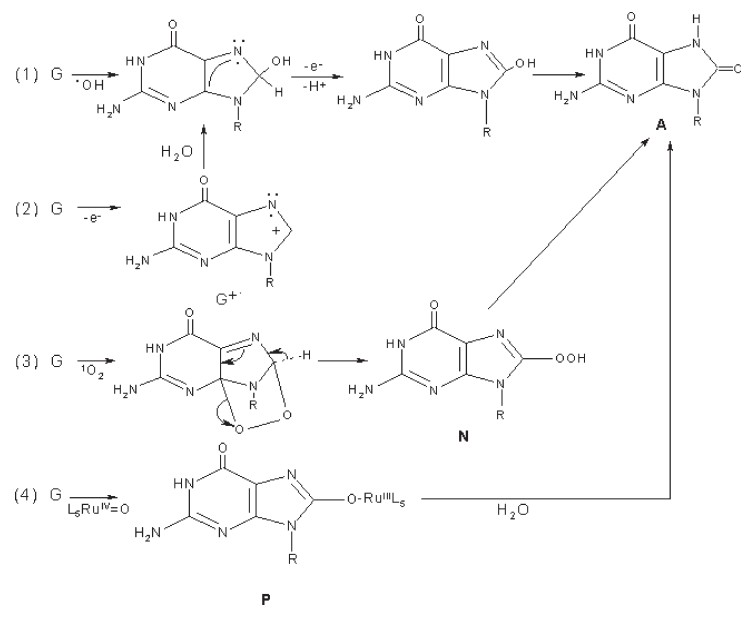

Figura 2. Mecanismos de reação para a formação da 8-oxodG a partir da guanina. (A) 8-oxodG (7,8-diidro-8-hidroxoguanina); (N) 8hidroperoxiguanina; $(\boldsymbol{P})$ intermediário de guanina e complexo de Rutênio (IV). R: ribose. Reproduzida da ref. 51 com permissão da "The American Chemical Society"

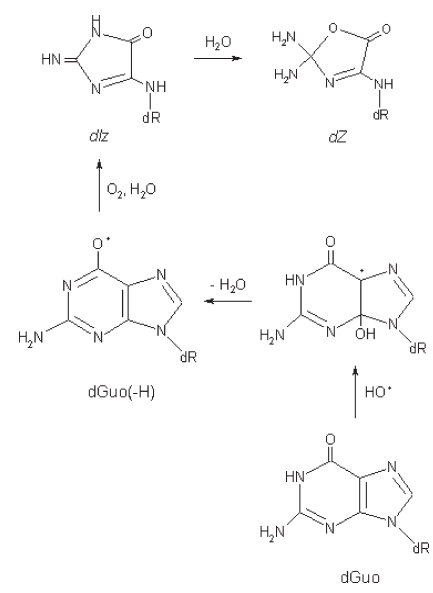

Figura 3. Produto principal da oxidação da dGuo por HO em solução aquosa aerada. dZ: 2, 2-diamino-4-[(2-deoxi- $\beta$-D-eritro-pentofuranosil) amino]5(2H)-oxazolona. dR: desoxirribose; dlZ: nucleosídeo Imidazolona. Reproduzida da ref. 81 com permissão da Elsevier

conforme mecanismo apresentado no Esquema I. Por ex., segundo Shi et al..$^{48}$ a autoxidação de $\mathrm{SO}_{3}^{2-}$ gera não só radicais $\mathrm{SO}_{3}{ }^{-}$ como também $\mathrm{HO}^{\prime}$, sendo ambos detectados por EPR. Esses radicais causam oxidação da dGuo, gerando 8-oxodGuo e quebras da dupla fita do DNA.

\section{Reação de purinas com HO•}

Informações importantes sobre a formação de lesões oxidativas na guanina têm sido obtidas em diversos estudos sobre os efeitos do HO em dGuo, oligonucleotídos e DNA isolado ${ }^{83}$.

$\mathrm{O}$ radical $\mathrm{HO}^{*}$ interage com a guanina pela adição preferencialmente nas posições $\mathrm{C}(8)$ e $\mathrm{C}(4)$ do anel para formar radicais 1 e 5 , respectivamente ${ }^{84}$ (Figuras 4 e 5).

Com dGuo, as gerações dos radicais 1 e 5 são 17 e 50-60\%, respectivamente, considerando que o radical 1 tem propriedades redutoras e o radical 5, propriedades oxidantes, a adição de $\mathrm{HO}^{*}$ à $\mathrm{C}(5)$ da guanina é um processo menos provável ${ }^{85}$. Na ausência de oxigênio, no radical 1 ocorre abertura do anel do radical com uma constante de velocidade de $2,0 \times 10^{-5} \mathrm{~s}^{-1}$ gerando o radical 2 (Figura 4). Na presença de agentes redutores, o radical 2 é convertido 
no nucleosídeo 2,6-diamino-4-hidroxi-5-formamidopirimidina (FapyG, Figura 4). Na presença de oxigênio ou agentes oxidantes, o radical 1 é convertido no produto persistente, 8-oxodGuo ( $\mathrm{Fi}$ gura 4), usado como marcador biológico de estresse oxidativo ${ }^{86,87}$. O radical 5 sofre uma reação de desidratação com uma constante de velocidade de $6,0 \times 10^{3} \mathrm{~s}^{-1}$ em $\mathrm{pH} 7$ para dar o radical oxidado 6 ou 7, dependendo do $\mathrm{pH}$ (Figura 5) com um valor de $\mathrm{pK}_{\mathrm{a}}$ de 3,9 para a dGuo ${ }^{84,86}$. O radical 6 , em $\mathrm{pH}$ neutro, reage lentamente com o oxigênio ${ }^{86}\left(\mathrm{k}<10^{6} \mathrm{M}^{-1} \mathrm{~s}^{-1}\right)$ para produzir a oxazolona ${ }^{87}$ (Figura 5). No entanto, no DNA, o radical guanina oxidado tem caráter iônico parcial em um $\mathrm{pH}$ neutro, devido à transferência parcial de um próton pela sua base complementar, a citosina ${ }^{85}$.
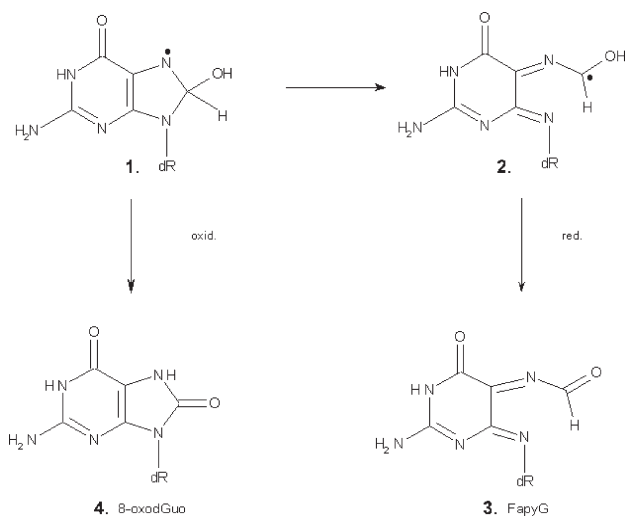

Figura 4. Produtos formados a partir da reação do radical HO com a guanina. (1) e (2) radicais de guanina; (3) FapyG (2,6-diamino-4-hidroxi-5formamidopirimidina); (4) 8-oxodGuo (8-oxo-7,8-diidro-2'-deoxiguanosina). dR: desoxirribose. Reproduzida da ref. 85 com permissão da Elsevier

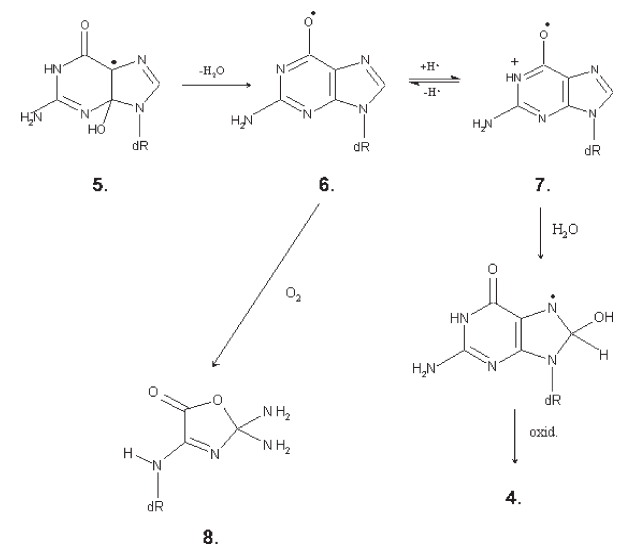

Figura 5. Produtos formados a partir da reação do radical $\mathrm{HO}$ com a guanina. (5), (6) e (7) radicais da guanina; (1) radical intermediário; (4) 8oxodGuo (8-oxo-7,8-diidro-2'-deoxiguanosina) e (8) produto oxazolona. dR: desoxirribose. Reproduzida da ref. $85 \mathrm{com}$ permissão da Elsevier

Outro caminho de reação para o radical 7 (Figura 5) é a hidratação $\left(\mathrm{k} \sim 17 \mathrm{~s}^{-1}\right)$ para gerar radical $1^{88}$, que em presença de oxidantes é convertido, entre outros produtos, a 8-oxodG (4). A 8-oxodG é o produto principal obtido a partir da oxidação de $\mathrm{DNA}^{89}$. O radical HO^ também interage com adenina por adição preferencialmente nas posições $\mathrm{C}(4)$ e $\mathrm{C}(8)$ do anel para dar os radicais 9 e 12 , respectivamente $^{84}$ (Figuras 6 e 7).

Com adenosina, as gerações dos radicais 9 e 12 (Figuras 6 e 7) são 30-35 e 37\%, respectivamente, relativos ao radical HO'. O radical 12 sofre uma reação de anel aberto na ausência de oxigênio para gerar o radical $13^{90}$ (Figura 7). Este último radical, na presença de agentes redutores, é convertido ao produto estável Fapy A (14) (Fi- gura 7). Na presença de oxigênio ou agentes oxidantes, o radical 12 é convertido finalmente a 8-oxodA, produto 15 (Figura 7).

O radical 9 sofre uma reação de desidratação com uma constante de velocidade de $2 \times 10^{4} \mathrm{~s}^{-1}$ para gerar o radical oxidado 10 (Figura 6), que tem um $\mathrm{pK}_{\mathrm{a}}<1{ }^{84}$. Portanto, o radical 10 não deveria ter caráter catiônico em DNA a pH neutro, não sendo esperado que se hidrate, produzindo finalmente 8-oxodA (15). O radical 10 reage com agentes redutores para regenerar adenina ${ }^{85}$. Se a guanina se encontra na cadeia adjacente ao radical 10, após uma rápida transferência intramolecular de elétrons, resulta na produção do radical oxidado de guanina (11) (Figura 6). Esta reação foi revelada unicamente em oligonucleotídeos ${ }^{91}$. A reação é termodinamicamente favorável, sendo os potenciais de redução de radicais oxidados de guanosina (radical 6 / guanina) e adenosina (radical 10 / adenina) iguais a 1,29 e 1,42 V (vs. E.N.H.), respectivamente ${ }^{92}$ (Tabela 1).

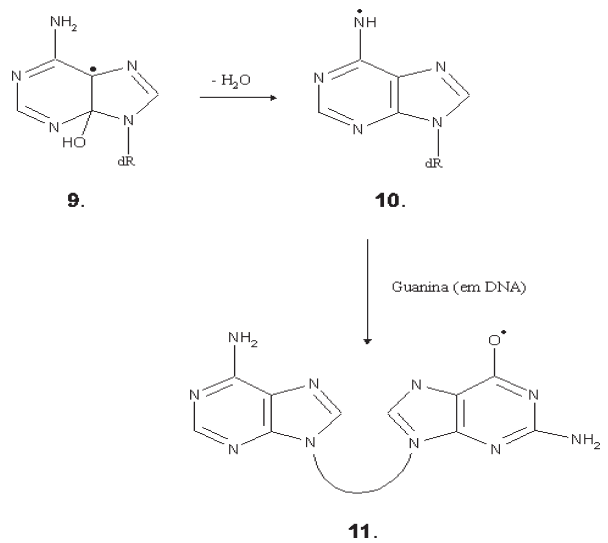

Figura 6. Produtos formados a partir da reação do radical $\mathrm{HO}$ com adenina. (9) e (10) radicais da adenina; (11) radical oxidado da guanina. dR: desoxirribose. Reproduzida da ref. 85 com permissão da Elsevier

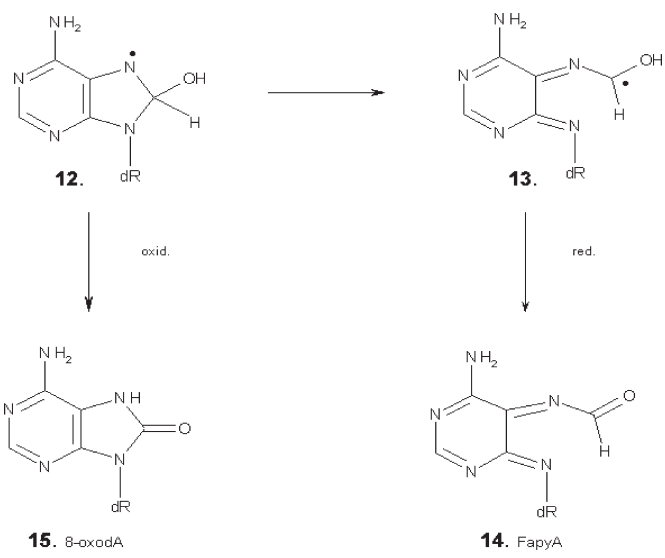

Figura 7. Produtos formados a partir da reação do radical $\mathrm{HO}$ com adenina. (12) e (13) radicais da adenina; (14) FapyA; (15) 8-oxodA. dR: desoxirribose. Reproduzida da ref. 85 com permissão da Elsevier

\section{Reação de pirimidinas com HO•}

Com pirimidinas, o radical $\mathrm{HO}^{\bullet}$ interage com as duplas ligações $\mathrm{C}(5)=\mathrm{C}(6)$ para produzir principalmente dois radicais, que são facilmente diferenciados por suas propriedades redox. $\mathrm{O}$ radical 5-hidroxi-6-il, que corresponde a mais de $70 \%$ do produto gerado a partir de $\mathrm{HO}^{*}$, é reduzido se o radical 6-hidroxi-6-il é oxida$\mathrm{do}^{84,85}$. Com timina, um radical produzido em menor rendimento é formado pela abstração do átomo $\mathrm{H}$ do seu grupo $-\mathrm{CH}_{3}$. Na ausência de oxigênio, esses radicais pirimidinas interagem por adição com 
oxigênio para produzir os adutos radicais peroxos correspondentes $^{85}$. Os adutos peroxos surgem a partir de $\mathrm{C}(5)-\mathrm{HO}$. Os adutos podem sofrer uma reação de abstração do átomo de hidrogênio do açúcar das vizinhanças $\left(\mathrm{k} \sim 1 \mathrm{~s}^{-1}\right)$. Se a abstração acontece no C(4)' deste açúcar vizinho, uma quebra da cadeia é produzida ${ }^{84}$.

\section{INTERAÇÃO ENTRE ALGUNS COMPLEXOS PEPTÍDICOS DE ÍONS DE COBRE(II) E DNA NA PRESENÇA DE PERÓXIDO DE HIDROGÊNIO ${ }^{93}$}

Uma interação entre complexos peptídicos de íons de cobre(II) e DNA foi observada a partir de dados espectrofotométricos. Em soluções contendo complexos de $\mathrm{Cu}$ (II) e DNA foram observados hipercromismo (aumento da absortividade molar), hipocromismo (diminuição da absortividade molar) ou batocromismo (deslocamento para a região do vermelho do comprimento de onda de absorção máxima) no $\mathrm{DNA}^{93}$. Esses efeitos foram atribuídos ao fato de que complexos de cobre(II) podem se ligar ao DNA dupla fita de diferentes modos, ligação através de hidrogênio, por forças de van der Waals ou coordenação entre os íons de cobre(II) dos complexos e as bases nitrogenadas do $\mathrm{DNA}^{93}$.

Nos estudos de complexos de $\mathrm{Cu}(\mathrm{II})$, em meio contendo peróxido de hidrogênio e DNA (Equações 40 - 43), a estrutura geométrica dos complexos que interagem com o DNA é uma propriedade muito importante que indicará indiretamente a extensão da lesão no $\mathrm{DNA}^{93,94}$. Desta forma, uma ligação forte entre o complexo de cobre (II) e DNA dupla fita garante uma proximidade maior dos radicais a serem formados e, conseqüentemente, a probabilidade de lesar mais acentuadamente a biomolécula. Entretanto, é importante ressaltar que a capacidade de lesar a dupla fita do DNA também dependerá da eficiência da formação de radicais li$\operatorname{vres}^{93}$. Assim, a extensão da ligação é somente um indicativo do que poderia influenciar na magnitude da lesão, mas não é uma característica definitiva. Por ex., os complexos $\left[\mathrm{Cu}(\mathrm{Im})_{4} \mathrm{Cl}\right] \mathrm{Cl}$ e $\left[\mathrm{Cu}(\mathrm{IDB})\left(\mathrm{NO}_{3}\right)_{2}\right]$ (Figuras $8 \mathrm{~A}$ e $8 \mathrm{~B}$ ) (ambos com estrutura piramidal de base quadrada), ligam-se fortemente ao DNA em comparação ao complexo $[\mathrm{Cu}(\mathrm{HTCD})] \mathrm{I}_{2}$ (estrutura quadrada plana) (Figura 8C), sendo a lesão no DNA maior na presença deste último complexo e $\mathrm{H}_{2} \mathrm{O}_{2}$. Portanto, o modo de ligação do complexo $\left[\mathrm{Cu}(\mathrm{HTCD}) \mathrm{I}_{2}\right.$ permite uma proximidade maior dos íons de cobre ao centro da molécula de $\mathrm{DNA}^{93}$.
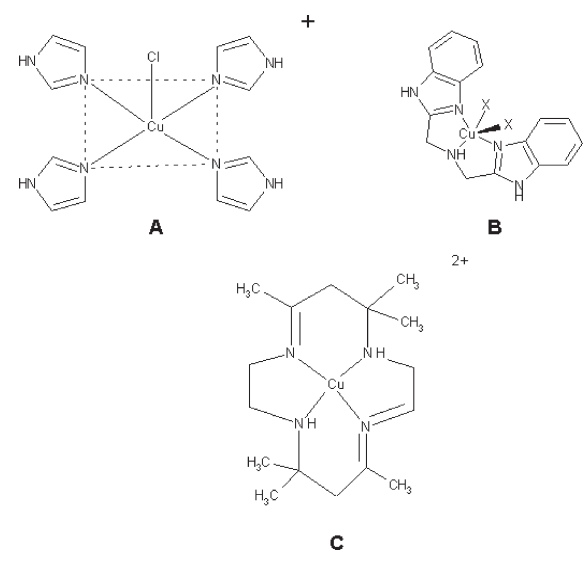

Figura 8. Complexos de cobre: (A) $\left[\mathrm{Cu}(\mathrm{Im})_{4} \mathrm{Cl}\right] \mathrm{Cl}$; (B) $\left[\mathrm{Cu}(\mathrm{IDB})\left(\mathrm{NO}_{3}\right)_{2}\right]$ e (C) $[\mathrm{Cu}(\mathrm{HTCD})] I_{2}$. Reproduzida da ref. 93 com permissão da Elsevier

Desta forma, foi sugerida a formação de uma ligação covalente ou não covalente de DNA - $\mathrm{Cu}$ (II)/ligante antes da formação dos radicais livres $(\mathrm{HO})^{93}$. Com base nesta idéia foi sugerido um mecanismo de lesão no DNA dupla fita a partir da formação do radi- cal HO (reação de Fenton ou Haber Weiss, Equações. 40 - 43) indicando uma interação inicial do complexo de cobre(II) com o DNA. Posteriormente, o $\mathrm{Cu}$ (II) ligado ao DNA é reduzido a $\mathrm{Cu}(\mathrm{I})$ por um redutor, e na presença de $\mathrm{H}_{2} \mathrm{O}_{2}$ há formação de radicais hidroxila muito próximos ao DNA. Finalmente, estes radicais reagem rapidamente com a desoxirribose adjacente do DNA, ocasionando a quebra da fita ${ }^{93}$.

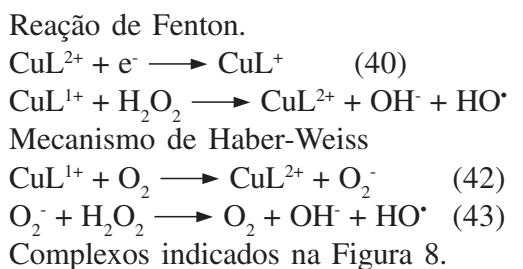

Finalmente, conclui-se que as lesões no DNA promovidas pela autoxidação de sulfito, na presença de íons metálicos de transição, claramente envolvem radicais de óxidos de enxofre $\left(\mathrm{SO}_{3}{ }^{-}, \mathrm{SO}_{4}{ }^{--}\right.$, $\mathrm{SO}_{5}^{-}$) e outras espécies ( $\mathrm{HSO}_{5}^{-}, \mathrm{HO}^{\circ}$ ) formadas durante este processo oxidativo. Os estudos aqui apresentados também indicaram que existem condições críticas ( $\mathrm{pH}$, concentração dos reagentes, natureza do íon metálico, ligante e concentração de oxigênio) a serem consideradas na etapa inicial da reação e na intensidade da lesão no $\mathrm{DNA}^{95}$. A identificação das espécies envolvidas nem sempre pode ser realizada com segurança, no entanto, estudos cinéticos combinados com equilíbrios de formação de íons complexos podem contribuir para um melhor entendimento da lesão oxidativa no DNA.

\section{AGRADECIMENTOS}

\section{Ao CNpq e à Fapesp.}

\section{REFERÊNCIAS}

1. Taylor, S. L.; Higley, N. A.; Bush, R. K.; Adv. Food Res. 1986, 30, 1.

2. Ermakov, A. N.; Poskrebyshev, G. A.; Purmal, A. P.; Kinet. Catal. 1997, 38, 295.

3. Papazian, R.; FDA Consumer Magazine 1996, 30-10, 35.

4. American Academy of Allergy and Immunology Committee on Adverse Reactions to Foods and National Institute of Allergy and Infectious Diseases. 1984, Adverse Reactions to Foods, U.S. Department of Health and Human Services, Public Health Service, National Institutes of Health, 1984, Publication No. 84-2442, US. Government Printing Office, Wahington, DC, USA.

5. Stammati, A.; Zanetti, S.; Pizzoferrato, L.; Quatrucci, E.; Tranquilli, G. B.; Food. Addit. Contam. 1992, 9, 551.

6. Shapiro, R.; Mutat. Res. 1977, 39, 149.

7. Lepentsiotis, V.; Domagala, J.; Grgic, I.; van Eldik, R.; Muller, J. G.; Burrows, C. J.; Inorg. Chem. 1999, 38, 3500.

8. Muller, J. G.; Burrows, C. J.; Inorg. Chim. Acta 1998, 276, 314.

9. Muller, J. G.; Hickerson, R. P.; Perez, R. J.; Burrows, C. J.; J. Amer. Chem. Soc. 1997, 119, 1501.

10. Coichev, N.; van Eldik, R.; New J. Chem. 1994, 18, 123.

11. Brandt, C.; van Eldik, R.; Chem. Rev. 1995, 95, 119.

12. Pezza, H. R.; Fernandes, C. F.; Suárez-Iha. M. E. V.; Coichev, N.; Quim. Nova 1999, 22, 529.

13. Chen, T. I.; Barron, C. H.; Ind. Eng. Chem. Fundam. 1972, 11, 466.

14. Duca, A.; Matei, F.; Ionescu, G.; Talanta 1980, $27,917$.

15. Hobson, D. B.; Richardson, P. J.; Hewitt, E. A.; Smith, I.; J. Chem. Soc. Faraday Trans. 1986, 82, 869.

16. Brinbleconbe, P.; Spedding, D. J.; Atmos. Environ. 1974, 8, 937.

17. Sato, T.; Goto, T.; Okabe, T.; Lawson, F.; Bull. Chem. Soc. Jpn. 1984, 57, 2082.

18. Brandt, C.; van Eldik, R.; Atmos. Environ. 1997, 31, 4247.

19. Huss, A.; Lim, P. K.; Eckert, C. A.; J. Phys. Chem. 1982, 86, 4229.

20. Ibusuki, T.; Barnes, H. M.; Atmos. Environ. 1984, 18, 145.

21. Backstrom, H. J.; Z. Phys. Chem. 1934, 25B, 122.

22. Carlyle, D. W.; J. Am. Chem. Soc. 1972, 94, 4525. 
23. Leite, H. M. S.; Coichev, N.; Neves, E. A.; Anal. Lett. 1996, 29, 2587.

24. Carvalho, L. B.; Crivelente, V. C. T.; Alipázaga, M. V.; Coichev, N.; Inorg. Reac. Mech. 2004, 5, 101.

25. van Eldik, R.; Harris, G. M.; Inorg. Chem. 1980, 19, 880.

26. Dellert-Ritter, M.; van Eldik, R.; Dalton Trans. 1992, 6, 1037.

27. Boyce, S. D.; Hoffmann, M. R.; Hong, P. A.; Moberly, L. M.; Environ. Sci. Technol. 1983, 17, 602.

28. Bobba, V. M.; Giraudi, G.; Mentasi, E.; Chemistry 1988, 13, 256.

29. Coichev, N.; van Eldik, R.; Inorg. Chem. 1991, 30, 2375.

30. Neves, E. A.; Coichev, N.; Gebert, J.; Klockow, D.; Fresenius Z. Anal. Chem. 1989, 335, 386

31. Lima, S.; Bonifácio, R. L.; Azzellini, G. C.; Coichev, N.; Talanta 2002 $56,547$.

32. Coichev, N.; van Eldik, R.; Inorg. Chim. Acta 1991, 185, 69.

33. Pezza, H. R.; Coichev, N.; J. Coord. Chem. 1999, 47, 107.

34. Pezza, H. R.; Bonifácio, R. L.; Coichev, N.; J. Chem. Res-M. 1999, 1520.

35. Moya, H. D.; Neves, E. A.; Coichev, N.; J. Chem. Educ. 1999, 76, 930.

36. Anast, J. M.; Margerum, D. W.; Inorg. Chem. 1981, 20, 2319.

37. Yoshida, D.; Moya, H. D.; Bonifácio, R. L.; Coichev, N.; Spectrosc. Lett. 1998, 31, 1495

38. Alipázaga M. V.; Coichev, N.; Anal. Lett. 2003, 36, 2255.

39. Alipázaga, M. V.; Moreno, R. G. M.; Coichev, N.; Dalton Trans. 2004, 13, 2036.

40. Alipázaga, M. V.; Bonifácio, R. L.; Kosminsky, L.; Bertotti, M.; Coichev, N.; J. Braz. Chem. Soc. 2003, 14, 713.

41. Alipázaga, M. V.; Kosminsky, L.; Bertotti, M.; Coichev, N.; Talanta 2002. 57,375 .

42. Alipázaga, M. V.; Coichev, N.; Dalton Trans. 2004, 2, 267.

43. Reddy, K. B.; Coichev, N.; van Eldik, R.; J. Chem. Soc. Chem. Commun. 1991, 481.

44. van Eldik, R.; Coichev, N.; Bal Reddy, K.; Gerhard, A.; Ber. Bunsenges Phys. Chem. 1992, 96, 478.

45. Coichev, N.; van Eldik, R.; Franz, D. A.; J. Chem. Educ. 1994, 71, 767.

46. Fronaeus, S.; Berglund, J.; Elding, L. I.; Inorg. Chem. 1998, 37, 4939.

47. Fronaeus, S.; Berglund, J.; Elding, L. I.; Inorg. Chem. 1993, 32, 4527.

48. Shi, X.; Mao, Y.; Biochem. and Biophys. Res. Commun. 1994, $205,141$.

49. Burrows, C. J.; Perez, R. J.; Muller, J. G.; Rokita, S. E.; Pure Appl. Chem. 1998, 70, 275.

50. Muller, J. G.; Zheng, P.; Rokita, S. E.; Burrows, C. J.; J. Am. Chem. Soc. 1996, 118, 2320

51. Burrows, C. J.; Muller, J. G.; Chem. Rev. 1998, 98, 1109.

52. Mottley, C.; Mason, R. P.; Chignell, C. F.; Sivarajah, K.; Eling, T. E.; J. Biol. Chem. 1982, 257, 5050

53. Sun, X.; Shi, X.; Dalal, N. S.; FEBS. Lett. 1992, 303, 213.

54. Yang, S. F.; Biochemistry 1970, 9, 5008.

55. Peiser, G. D.; Yang, S. F.; J. Agric. Food Chem. 1979, 27, 446.

56. Southerland, W. M.; Akogveram, C. O.; Toghrol, F.; Sloan, L.; Scherrer, R.; J. Toxicol. Environ. Health 1982, 10, 479.

57. Lizada, M. C. C.; Yang, S. F.; Lipids 1981, 16, 189.

58. Kapuss, H.; Arch. Toxicol. 1987, 60, 144.

59. Kawanishi, S.; Yamamoto, K.; Inoue, S.; Biochem. Pharmacol. 1989, 38, 3491.

60. Shi, X.; J. Inorg. Biochem. 1994, 56, 155.

61. Wietzerbin, J.; Muller, J. G.; Jameton, R. A.; Pratviel, G.; Bernadou, J.; Meunier, B.; Burrows, C. J.; Inorg. Chem. 1999, 38, 4123.
62. Hayatsu, H.; Miller, R. C.; Biochem. Biophis. Res. Commun. 1972, 46, 120. 63. Inoue, S.; Kawanishi, S.; Cancer Res. 1987, 47, 6522.

64. Hickerson, R. P.; Prat, F.; Muller, J. G.; Foote, C. S.; Burrows, C. J.; J. Am. Chem. Soc. 1999, 121, 9423.

65. Mclachlan, G. A.; Muller, J. G.; Rokita, S. E.; Burrows, C. J.; Inorg. Chim. Acta. 1996, 251, 193.

66. Hickerson, R. P.; Watkins-Sims, C. D.; Burrows, C. J.; Atkins, J. F.; Gesteland, R. F.; Felden, B. J.; Mol. Biol. 1998, 279, 577.

67. Zheng, P.; Burrows, C. J.; Rokita, S. E.; Biochemistry 1998, 37, 2207.

68. Gill, G.; Richter-Rusli, A. A.; Ghosh, M.; Burrows, C. J.; Rokita, S. E.; Chem. Res. Toxicol. 1997, 10, 302.

69. Stuart, N. J.; Goerges, A. L.; Zaleski, J. M.; Inorg. Chem. 2000, 39, 5976.

70. Moreno, R. G. M.; Alipázaga, M. V.; Medeiros, M. H. G.; Coichev, N.; Dalton Trans. 2005, 6, 1101.

71. Moreno, R. G. M.; Alipázaga, M. V.; Linares, E.; Augusto, O.; Gomes, F. O.; Medeiros, M. H. G.; Coichev, N.; Dalton Trans., submetido.

72. Ross, A. S.; Burrows, C. J.; Tetrahedron Lett. 1997, 38, 2805.

73. Ross, A. S.; Burrows, C. J.; Nucleic Ac. Res. 1996, 24, 5062.

74. Schultze - Frohlinde, D.; Hildebrandt, K.; Free Radicals in Synthesis and Biology, NATO ASI Series, Ed. Kluwer: Dordrecht, 1989.

75. Von, C. S.; Hagen, U.; Schön-Bopp, A.; Shulte-Frohlinde, D., Em Advances in Radiation Biology; Lett, J. T.; Adler, H., eds.; Academic Press: New York, 1981, vol. 9, p. 109-142.

76. Nakayama, T.; Kodama, M.; Nagata, C.; Agric. Biol. Chem. 1984, 48, 571.

77. Minisci, F.; Citterio, A.; Giordano, C.; Acc. Chem. Res. 1983, 16, 27.

78. O'neill, P.; Davies, S. E.; Int. J. Radiat. Biol. 1987, 52, 577.

79. Neta, P.; Huie, R, E.; Ross, A. B.; J. Phys. Chem. Ref. Data 1988, 17, 1027.

80. Hickerson, R. P.; Chepanoske, C. L.; Williams, S. D.; David, S. S.; Burrows, C. J.; J. Am. Chem. Soc. 1999, 121, 9901.

81. Cadet, J.; Douki, T.; Gasparutto, D.; Ravanat, J. L.; Mutat. Res. 2003, 531, 5.

82. Collins, A. R.; Cadet, J.; Moller, L.; Poulsen, H. E.; Viña, J.; Arch. Biochem. Biophys. 2004, 423, 57.

83. Martinez, G. R.; Loureiro, A. P. M.; Marques, A. S.; Miyamoto, S.; Yamaguchi, L. F.; Onuki, J.; Almeida, E. A.; Garcia, C. C. M.; Barbosa, L. F.; Medeiros, M. H. G.; Di Mascio, P.; Mutat. Res. 2003, 544, 115.

84. O'Neill, P.; Fielden, E. M.; Adv. Radiat. Biol. 1993, 17, 53.

85. Chatgilialoglu, C.; O'Neill, P.; Exp. Geront. 2001, 36, 1459.

86. Candeias, L. P.; Steenken, S.; Chem. Eur. J. 2000, 6, 475.

87. Douki, T.; Spinelli, S.; Ravanat, J. L.; Cadet, J.; J. Chem. Soc. Perkin Trans. 1999, 2, 1875.

88. Melvin, T.; Botchway, S. W.; Parker, A. W.; O’Neill, P.; J. Am. Chem. Soc. 1996, 118,10031

89. Melvin, T.; Cunniffe, S. M. T.; O’Neill, P.; Parker, A.; Roldan-Arjona, T.; Nucl. Acids. Res. 1998, 26, 4935.

90. Viera, A. J. S. C.; Steenken, S.; J. Am. Chem. Soc. 1990, 112, 6986

91. Bamatraf, M. M. M.; O’neill, P.; Rao, B. S. M.; J. Phys. Chem. B. 2000, 104, 636.

92. Steenken, S.; Jovanovic, S. V.; J. Am. Chem. Soc. 1997, 119, 617.

93. Liu, C.; Zhou, J.; Li, Q.; Wang, L.; Liao, Z.; XU, H.; J. Inorg. Biochem. 1999, $75,233$.

94. Liu, J.; Zhang, T.; Lu, T.; Qu, L.; Zhou, H.; Zhang, Q.; Ji, L.; J. Inorg. Biochem. 2002, 91, 269

95. Alipázaga, M. V.; Moreno, R. G. M.; Linares, E.; Medeiros, M. H. G.; Coichev, N.; Dalton Trans. 2005, 23, 3738. 